\title{
Biomechanical performance of Bio Cross-Pin and EndoButton for ACL reconstruction at femoral side: a porcine model
}

Ari Digiácomo Ocampo Moré, André Luiz Almeida Pizzolatti, Eduardo Alberto Fancello, Carlos Rodrigo de Mello Roesler*

Abstract Introduction: The method of graft fixation is critical in anterior cruciate ligament (ACL) reconstruction surgery. Success of surgery is totally dependent on the ability of the implant to secure the graft inside the bone tunnel until complete graft integration. The principle of EndoButton is based on the cortical suspension of the graft. The Cross-Pin is based on graft expansion. The aim of this study was to evaluate the biomechanical performance of EndoButton and Bio Cross-Pin to fix the hamstring graft at femoral side of porcine knee joints and evaluate whether they are able to support of loading applied on graft during immediate post-operative tasks. Methods: Fourteen ACL reconstructions were carried out in porcine femurs fixing superficial flexor tendons with Titanium EndoButton $(n=7)$ and with $6 \times 50 \mathrm{~mm}$ HA/PLLA Bio Cross-Pin $(\mathrm{n}=7)$. A cyclic loading test was applied with $50-250 \mathrm{~N}$ of tensile force at $1 \mathrm{~Hz}$ for 1000 cycles. The displacement was measured at 20, 100,500 and 1000 load cycles to quantify the slippage of the graft during the test. Single-cycle load-to-failure test was performed at $50 \mathrm{~N} / \mathrm{mm}$ to measure fixation strength. Results: The laxity during cyclic loading and the displacement to failure during single-cycle test were lower for the Bio Cross-Pin fixation $(8.21 \pm 1.72 \mathrm{~mm})$ than the EndoButton $(11.20 \pm 2.00 \mathrm{~mm})$. The Bio Cross-Pin $\left(112.22 \pm 21.20 \mathrm{~N}^{-\mathrm{mm}^{-1}}\right)$ was significantly stiffer than the EndoButton fixation $\left(60.50 \pm 10.38 \mathrm{~N} \cdot \mathrm{mm}^{-1}\right)$. There was no significant difference between Bio Cross-Pin (failure loading: $758.29 \pm 188.05 \mathrm{~N}$; yield loading: $713.67 \pm 192.56 \mathrm{~N}$ ) and EndoButton strength (failure loading: $672.52 \pm 66.56 \mathrm{~N}$; yield loading: $599.91 \pm 59.64 \mathrm{~N}$ ). Both are able to support the immediate post-operative loading applied $(445 \mathrm{~N})$. Conclusion: The results obtained in this experiment indicate that the Bio Cross-Pin technique promote stiffer fixation during cyclic loading as compared with EndoButton. Both techniques are able to support the immediate post-operative loading applied.

Keywords: Biomechanics, ACL reconstruction, EndoButton, Bioabsorbable Cross-Pin.

\section{Introduction}

The anterior cruciate ligament (ACL) replacement with hamstring graft has been widely performed with positive results. This procedure, however, requires great care at postoperative period. Although the four-stranded hamstrings have higher strength and stiffness than patellar tendon (Hamner et al., 1999), the integration into the bone is delayed due to the lack of bone block (Blickenstaff et al., 1997; Rodeo et al., 1993; Weiler et al., 2002a, b). This factor makes the early postoperative period a critical time for successful surgery (Becker et al., 2001; Brown et al., 1996; Wilson et al., 1999). The fixation of graft is totally dependent of implant performance during this period. A poor fixation can lead to graft slippage and result in knee instability or failure of fixation (Fu et al., 1999; Giurea et al., 1999; Magen et al., 1999; Shen et al., 2010). Furthermore, the slippage impairs the integration and ligamentization process (Rodeo et al., 1993, 2006).
EndoButton and Cross-pin are techniques based on different mechanical principles. The graft is suspended inside the bone tunnel by both techniques. The anchor point, however, is different. EndoButton is an extra-articular device made of metallic button and a polyurethane ribbon (Endotape). The button is supported by the external cortical portion of the bone Endotape links the graft to the not supported central part of the metallic button. The Cross-Pin is an intra-articular device that traverses the joint and is stabilized with one tip fixed to the cortical wall and the other fixed inside cancellous bone. The graft passes around this pin to be fixed. During the graft tension, the button and the pin are submitted to bending forces (Figure 1). The diameter of Cross-Pin is higher than Endotape, increasing the volume when the tendon loops. In theory, this effect causes expansion and compression of the graft against the tunnel wall resulting in highest strength (Milano et al., 2006).

Previous studies have shown that the interference screws fixation on tibia is the weak point in ACL 

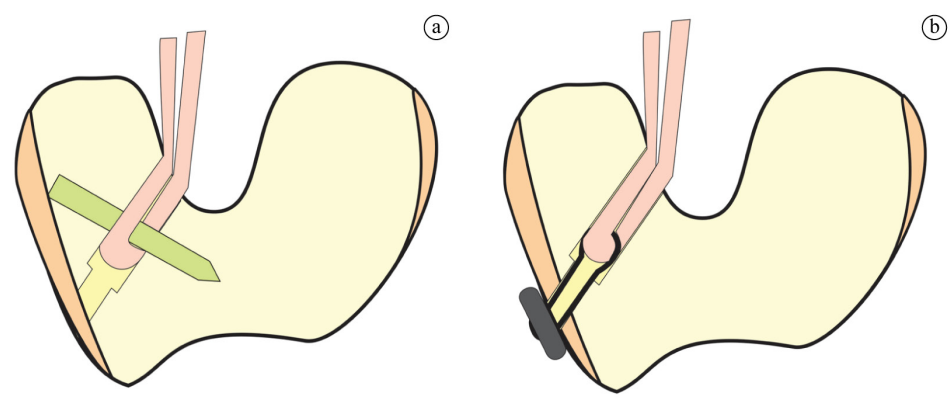

Figure 1. Mechanical methods of graft fixation. Left: Bio Cross-Pin (one cortical support point). Right: EndoButton (external cortical support point).

reconstruction when Bio Cross-Pin or EndoButton are used at femoral site (Shen et al., 2010). However, other methods of fixation on tibia such as Washer Loc and Tandem Washer have higher strength compared to Bio Cross-Pin or EndoButton (Kousa et al., 2003a; Kousa et al., 2003b; Magen et al., 1999). The femoral site becomes the weak point in this case. Therefore, the aim of this study was to assess the mechanical properties and the failure mode of Bio Cross-Pin and EndoButton with respect to the fixation of Hamstring graft. Our hypothesis was that different mechanical principle to secure the graft inside the bone tunnel results in different performances not being able to support post-operative loading. A porcine model was used to compare the laxity, the strength, the linear stiffness and the energy associated with each technique. Therefore, to evaluate the Cross-Pin and EndoButton performance for femoral fixation we apply the load directly on the graft.

\section{Methods}

Fourteen porcine knees of Landrace specimens with 2 years old and $400 \mathrm{~kg}$ weight were purchased from a commercial slaughterhouse in the state ready for consumption. They were harvested and stored at $-20^{\circ} \mathrm{C}$. This method allowed for harvesting of the soft tissue. Each femur was dissected and the superficial flexor tendon with approximately $5 \mathrm{~mm}$ diameter was extracted and used as a double graft. The use of the autograft instead of an artificial graft was preferred to mimic the clinical practice of use a graft retrieved from the patient. These grafts were then fixed to the femurs by the two fixation techniques: Titanium EndoButton linked with $30 \mathrm{~mm}$ polyurethane Endotape $(\mathrm{n}=7)$ and by Bio Cross-Pin HA/PLLA $70306 \times 50 \mathrm{~mm}$ $(\mathrm{n}=7)$ (Figure 2).

\section{Fixation technique}

The fixation procedure followed the same clinical protocol established for ACL reconstruction at

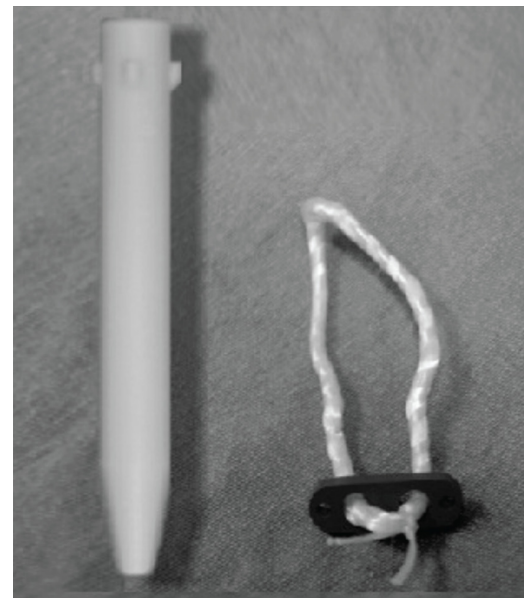

Figure 2. Bio Cross-Pin HA/PLLA $70306 \times 50 \mathrm{~mm}$ and Titanium EndoButton with $30 \mathrm{~mm}$ Polyurethane Endotape.

femoral side of human knees. A $6 \mathrm{~mm}$ over-the-top guiding device was used to locate the anatomical ACL insertion. The tunnel was drilled to match the graft diameter. A $6 \mathrm{~mm}$ diameter bone tunnel was drilled in inside-out technique to the EndoButton fixation. After this, a $30 \mathrm{~mm}$ tunnel was drilled with a $9 \mathrm{~mm}$ diameter for the graft positioning. On the Bio Cross-Pin fixation a $9 \mathrm{~mm}$ tunnel diameter was drilled for the graft positioning.

\section{Mechanical testing}

Immediately after the graft fixation, each femur was clamped to a custom device with bone cement (PMMA) and screws. This device was then placed in the servo-hydraulic testing machine (Brasvalvulas ${ }^{\circledR}$, São Paulo, Brazil) to guarantee the alignment between the tunnel axis and loading direction. Therefore, the testing was conducted in a worst condition scenario. The free end of the graft was fixed in the load cell leaving a gage length of $30 \mathrm{~mm}$ to mimic the human intra articular ACL length (Figure 3). Each specimen was then submitted to cyclic and single-cyclic loading-to-failure test. 
The cyclic test started with a preconditioning static tensile load of $50 \mathrm{~N}$ for $2 \mathrm{~min}$ followed by 1000 load cycles at $1 \mathrm{~Hz}$ between $50 \mathrm{~N}$ and $250 \mathrm{~N}$. The slippage of the graft-fixation device interface was measured indirectly through the graft lengthening after 20, 100, 500 and 1000 load cycles. This measurement combined the effect of the fixation device slippage and tendon stretch. The procedure was sufficiently accurate for the purposes of this study, in accordance with clinical practice (Kousa et al., 2003a). Failure during cyclical loading was assumed to occur in cases in which a complete slippage of the fixation device was observed. The specimens that did not fail were then submitted to a single-cycle load-to-failure test with a force rate of $50 \mathrm{~mm} / \mathrm{min}$ after the static preconditioning load. The values for the ultimate failure load, yield point load, displacement at ultimate failure load, displacement at yield load, linear stiffness, and energy were obtained from the load-displacement curves $(200 \mathrm{~Hz}$ sampling rate). The force $\mathrm{x}$ displacement curves was used to calculate these variables because we are not focusing the graft strain but the mechanical behavior of the whole system bone-graft-implant. The specimens were kept moistened by spraying with physiological solution $(0.9 \% \mathrm{NaCl})$.

\section{Statistical analysis}

A two-way split-plot ANOVA was used (fixation technique - between factor; and displacement by cycles - within factor) to test laxity during cyclic loading. The $t$ student test was used to compare the ultimate failure load, the displacement at ultimate failure load, the yield load, the displacement at yield load, and energy between the two graft fixation techniques during the single-cycle loading test. The Wilcoxon rank sum test was used to compare the linear stiffness variable. The probability level was set at 0.05 .

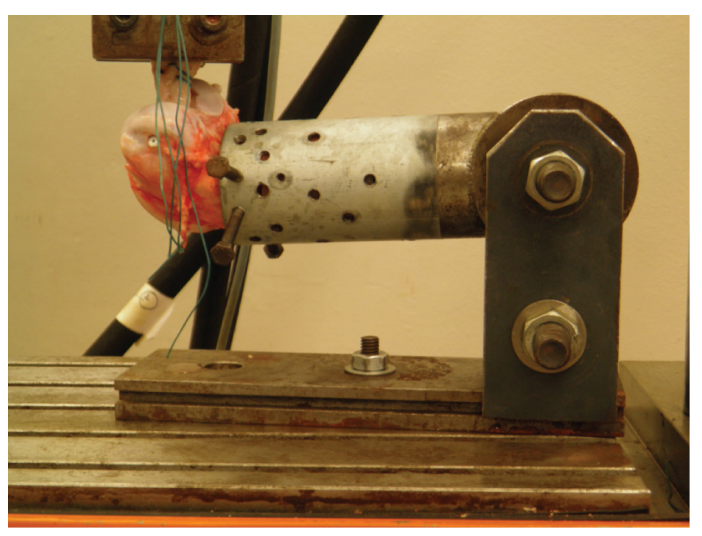

Figure 3. Position of femur during biomechanical test.

\section{Results}

No fixation devices failed during the cyclic loading test. The Bio Cross-Pin displacement was lower than EndoButton $(\mathrm{F}=6.92 ; \mathrm{P}=0.011)$ (Figure 4). The interaction between the fixation methods and cycles numbers, however, was not significant $(\mathrm{F}=0.66$; $\mathrm{P}=0.61$ ), showing that the numbers of cycles chosen for the test did not change the pattern of displacement between the two fixation methods.

Table 1 shows the results of single-cyclic load-to-failure test. No significant difference of ultimate failure load, yield load, and energy was observed between the Bio Cross-Pin and EndoButton fixation. The EndoButton revealed a smaller standard deviation of ultimate failure load and yield load. The mean displacement at ultimate failure load and displacement at yield load for Bio Cross-Pin was significantly lower than EndoButton. The Bio Cross-Pin technique showed significantly higher linear stiffness than the EndoButton.

The Endotape rupture was the most common failure mode. This failure mode occurred in 5 cases. The EndoButton was pulled out of the bone tunnel with plastic deformation of the button and left intact the Endotape in 2 cases. The Bio Cross-Pin broke in 5 cases, and the tendon failed in 2 cases.

\section{Discussion}

Studies in animal models have been widely realized to understand the biomechanical performance of several devices to fix the hamstring tendons in the femoral side in ACL reconstruction. A variety of testing parameters were used in these studies, including the use of femur-graft-tibia complex, the direction of pulling out the tendon, the rate of loading, and cyclic test protocol. However, the interpretation of implant performance at femoral site testing the whole complex may be difficult since that the fixation on the tibia fail before that on femur fails (Shen et al., 2010).

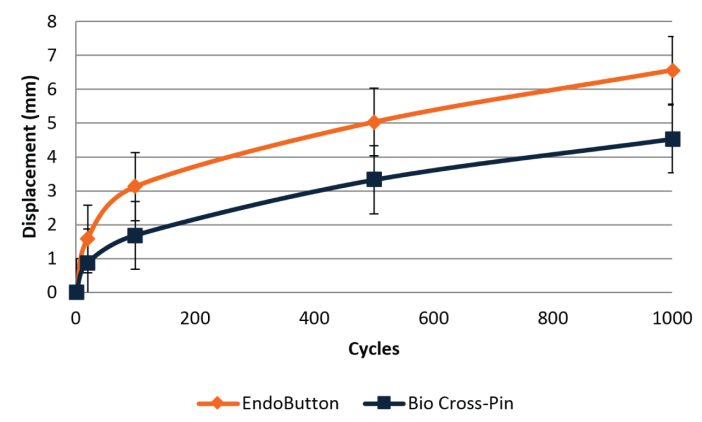

Figure 4. Average and standard deviation displacement of fixations during cyclical loading test. 
Table 1. Results of single-cycle failure-to-load test (Mean $\pm \mathrm{SD}$ ).

\begin{tabular}{lccc}
\hline & EndoButton $(\mathbf{n}=\mathbf{7})$ & Bio Cross-Pin $(\mathbf{n}=\mathbf{7})$ & p-value \\
\hline Ultimate failure load (N) & $672.52 \pm 66.56$ & $758.29 \pm 188.05$ & 0.2775 \\
Yield load (N) & $599.91 \pm 59.64$ & $713.67 \pm 192.56$ & 0.2140 \\
Displacement at failure (mm) & $11.20 \pm 2.00$ & $8.21 \pm 1.72$ & 0.0113 \\
Displacement at yield (mm) & $9.34 \pm 1.01$ & $6.66 \pm 3.33$ & 0.0053 \\
Linear stiffness (N/mm) & $60.50 \pm 10.38$ & $112.22 \pm 21.20$ & $0.0006^{*}$ \\
Energy (N.m) & $4.34 \pm 1.13$ & $3.60 \pm 1.43$ & 0.3043 \\
\hline
\end{tabular}

* - Wilcoxon rank sum test.

Therefore, the best way to assess the Bio Cross-Pin and EndoButton performance is to apply the loading directly at the graft. The existence of different methods makes it difficult to compare results. Despite a lack of similar methods, however, the results obtained at present work were similar with others from literature (Ahmad et al., 2004; Milano et al., 2006; Miyata et al., 2000; Rodríguez et al., 2014; Shen et al., 2010).

Our data showed that the Bio Cross-Pin fixation had lower laxity during cyclic loading than EndoButton. This superior performance means that the Bio Cross-Pin is more secure to support the loads applied during aggressive rehabilitation protocol. The laxity is related to loss of fixation by elongation of the graft, graft slippage, and plastic deformation of device. The sum of these factors may increase the graft micromovement and delay graft healing (Fu et al., 1999). The elongation of polyurethane Endotape may be responsible for the high displacement occurring with the EndoButton (Höher et al., 2000). Previous studies have shown that the biomechanical performance of the Bio Cross-Pin is superior that the EndoButton during cyclic and failure loading test (Ahmad et al., 2004; Rodríguez et al., 2014; Shen et al., 2010).

Despite any difference in strength observed during the failure test, Bio Cross-Pin was stiffer than EndoButton. In theory, the stiffness is an important variable to be considered. The fixation device should promote stiffness near the native ACL to avoid an excessive graft motion and knee laxity until graft integration, (To et al., 1999; Wu et al., 2009). A lower stiffness can, therefore, increase the displacement associated with anterior translation and may result in an unstable knee. There is consensus in the literature that the EndoButton have less stiffness than the Bio Cross-Pin (Milano et al., 2006; Rodríguez et al., 2014; Trump et al., 2011). Considering the energy that the femur-graft complex has absorbed up to the point of fixation failure, there was not differences between the both techniques evaluated.

The yield load has been advocated as the most important variable to be evaluated in the performance of fixation (Kousa et al., 2003a). In the present approach, the yield load is assumed to be the last point of linear region of load-displacement curve. Theoricaly, this point represents the fixation resistance before yielding. The first significant slippage of the graft occurs at this point. The stiffness decreases and the fixation tends to fail. The mean yield load for the Bio Cross-Pin was significantly higher than those for the EndoButton. The Endobutton showed a yield point very close to the failure load when the endotape broke (Figure 5). It happened in 5 cases. In two cases, the button pulled out the bone tunel with visible plastic deformation. When the failure did not occur in the Endotape, the displacement-load curve showed a different pattern. The yield point was located away from the failure load. The Bio Cross-Pin broke in all cases tested. This failure mode was similar to Rodríguez et al. (2014).

The yield loading displayed by both fixations was sufficient to support the loading applied during daily tasks and accelerated rehabilitation programs. Morrison (1970) reported $169 \mathrm{~N}$ as the ACL force during normal level walking. Noyes et al. (1984) estimated that the maximum force on the graft fixation device occurs while descending stairs and is approximately $445 \mathrm{~N}$. Previous studies have shown that ligament loads of this magnitude can be generated during quadriceps muscle contraction at full knee extension (Rupp et al., 1999). All of the constructs, therefore, can be considered to be secure enough for their intended use.

It is worth noting that some methods used in this experiment should be highlighted. One is the use of animal tissues. The porcine bone does not have the same bone mineral density as a healthy human bone. Previous studies have observed that the porcine bone did not resist the load applied. As a result, the button pulled out from the cortical bone (Ahmad et al., 2004; Rylander et al., 2014). Studies performed with human bone have not described this failure mode (Kousa et al., 2003a). Furthermore, the bone quality (Brown et al., 2004) and the button position on the femur (Conner et al., 2010) may alter the failure mode device. The advantage of using animal bone is its mineral density likeness and easy acquisition. The second aspect to be noted is the direction of bone tunnel axis during graft tension testing. The method 

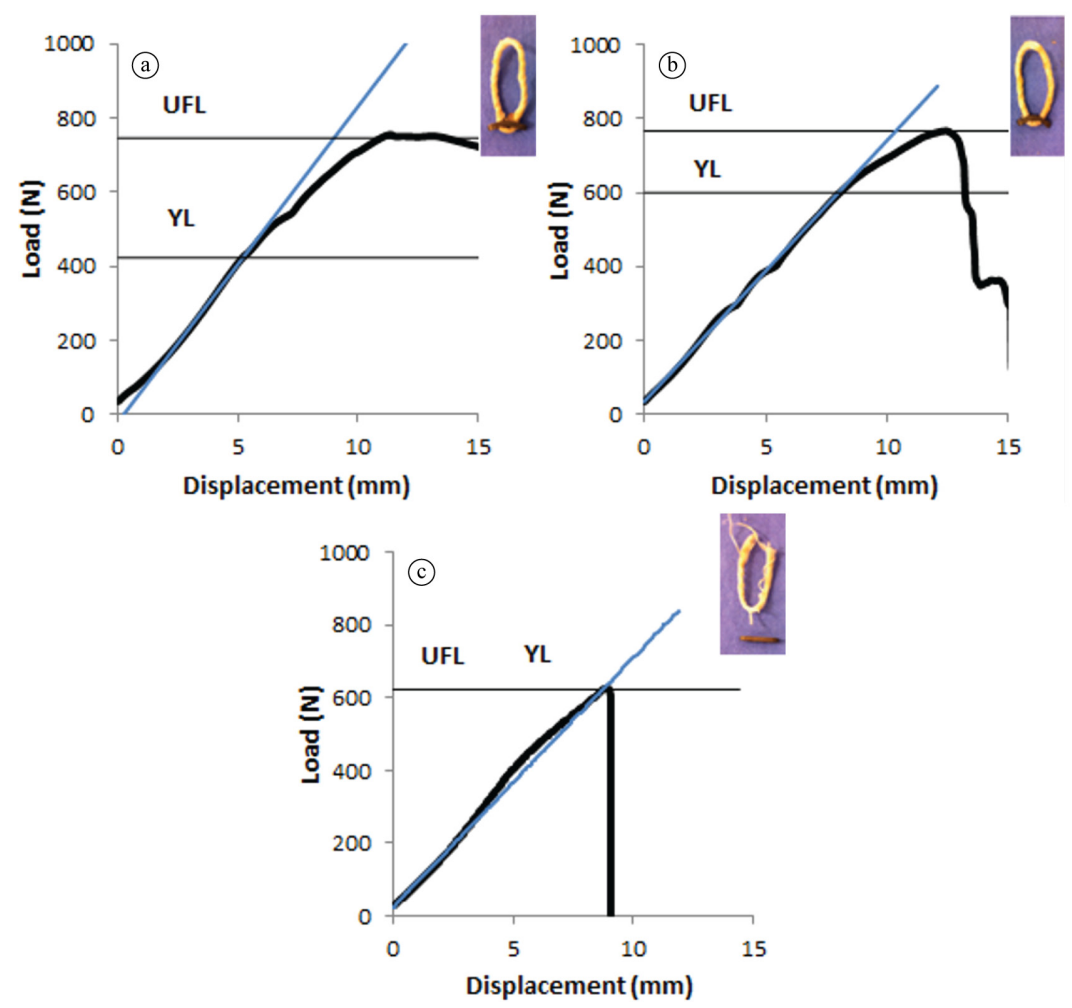

Figure 5. Yield Load and Ultimate Failure Load of EndoButton specimens that failed in different modes. (a) and (b) plastic bending of button; (c) Endotape rupture.

used in our study did not represent the functional loading applied to the graft during flexion-extension movement (Zhang et al., 2007). Therefore, the results do not warrant comparison to a clinical situation. These results, however, help us understand the biomechanical performance of the fixation, when submiting the device to a worst case condition.

The results obtained indicate that both types of fixations analyzed in this study showed sufficient strength to resist the loads applied during functional activities in the early intensive rehabilitation. However, the Bio Cross-Pin performance was the best. The laxity at cyclic test was lower, and the linear stiffness was higher than those for EndoButton. The main failure mode of EndoButton was endotape rupture while Bio Cross-Pin broke in all cases. Further research is needed to determine the clinical relevance of these findings relating the ACL replacement at femoral side.

\section{Acknowledgements}

The authors would like to thank FAPESC, FINEP and $\mathrm{CNPq}$ for the financial support.

\section{References}

Ahmad CS, Gardner TR, Groh M, Arnouk J, Levine WN. Mechanical Properties of Soft Tissue Femoral Fixation Devices for Anterior Cruciate Ligament Reconstruction. The American Journal of Sports Medicine. 2004; 32(3):635-40. http://dx.doi.org/10.1177/0363546503261714. PMid:15090378.

Becker R, Voigt D, Stärke C, Heymann M, Wilson GA, Nebelung W. Biomechanical properties of quadruple tendon and patellar tendon femoral fixation techniques. Knee Surgery, Sports Traumatology, Arthroscopy. 2001; 9(6):337-42. http://dx.doi.org/10.1007/s001670100223. PMid:11734869.

Blickenstaff KR, Grana WA, Egle D. Analysis of a semitendinosus autograft in a rabbit model. The American Journal of Sports Medicine. 1997; 25(4):554-9. http:// dx.doi.org/10.1177/036354659702500420. PMid:9240991.

Brown GA, Peña F, Grøntvedt T, Labadie D, Engebretsen L. Fixation strength of interference screw fixation in bovine, young human, and elderly human cadaver knees: influence of insertion torque, tunnel-bone block gap, and interference. Knee Surgery Sports Traumatology. 1996; 3(4):238-44. http://dx.doi.org/10.1007/BF01466626. PMid:8739721.

Brown CH Jr, David RW, Hecker AT, Ferragamo M. FGraftbone motion and tensile properties of hamstring and patellar tendon anterior cruciate ligament femoral graft fixation 
under cyclic loading. Journal of Arthroscopy and Related Surgery. 2004; 20(9):922-35. http://dx.doi.org/10.1007/ BF01466626. PMid:8739721.

Conner CS, Perez BA, Morris RP, Buckner JW, Buford WL, Ivey FM. Three femoral fixation devices for anterior cruciate ligament reconstruction: Comparison of fixation on the lateral cortex versus the anterior cortex. Journal of Arthroscopy and Related Surgery. 2010; 26(6):796-807. http:// dx.doi.org/10.1016/j.arthro.2009.10.015. PMid:20511038.

Fu FH, Bennett CH, Lattermann C. Current concepts current trends in anterior cruciate ligament peconstruction - Part 1: biology and biomechanics of reconstruction. The American Journal of Sports Medicine. 1999; 27(6):821-30. PMid:10569374.

Giurea M, Zorilla P, Amis AA, Aichroth P. Comparative pull-out and cyclic-loading strength tests of anchorage of hamstring tendon grafts in anterior cruciate ligament reconstruction. The American Journal of Sports Medicine. 1999; 27(5):621-5. PMid:10496580.

Hamner DL, Brown CH Jr, Steiner ME, Hecker AT, Hayes WC. Hamstring tendon grafts for reconstruction of the anterior cruciate ligament: biomechanical evaluation of the use of multiple strands and tensioning techniques. The Journal of Bone and Joint Surgery. 1999; 81(4):549-57. PMid:10225801.

Höher J, Scheffler SU, Withrow JD, Livesay GA, Debski RE, Fu FH, Woo SL. Mechanical behavior of two hamstring graft constructs for reconstruction of the anterior cruciate ligament. Journal of Orthopaedic Research. 2000; 18(3):456-61. http://dx.doi.org/10.1002/jor.1100180319. PMid:10937634.

Kousa P, Järvinen TLN, Vihavainen M, Kannus P. The fixation strength of six hamstring tendon graft fixation devices in anterior cruciate ligament reconstruction: Part I: Femoral site. The American Journal of Sports Medicine. 2003a; 31:174-81.

Kousa P, Järvinen TLN, Vihavainen M, Kannus P, Järvinen $M$. The fixation strength of six hamstring tendon graft fixation devices in anterior cruciate ligament reconstruction: Part II - Tibial site. The American Journal of Sports Medicine. 2003b; 31(2):182-8. PMid:12642250.

Magen HE, Howell SM, Hull ML. Structural properties of six tibial fixation methods for anterior cruciate ligament soft tissue grafts. The American Journal of Sports Medicine. 1999; 27(1):35-43. PMid:9934416.

Milano G, Mulas PD, Ziranu F, Piras S, Manunta A, Fabbriciani C. Comparison between different femoral fixation devices for ACL reconstruction with doubled hamstring tendon graft: a biomechanical analysis. The Journal of Arthroscopic \& Related Surgery. 2006; 22(6):660-8. http:// dx.doi.org/10.1016/j.arthro.2006.04.082. PMid:16762706.

Miyata K, Yasuda K, Kondo E, Nakano H, Kimura S, Hara N. Biomechanical comparisons of anterior cruciate ligament: reconstruction procedures with flexor tendon graft. Journal of Orthopaedic Science. 2000; 5(6):585-92. http://dx.doi. org/10.1007/s007760070010. PMid:11180923.

Morrison JB. The mechanics of the knee joint in relation to normal walking. Journal of Biomechanics. 1970; 3(1):5161. http://dx.doi.org/10.1016/0021-9290(70)90050-3. PMid:5521530.
Noyes FR, Butler DL, Grood ES, Zernicke RF, Hefzy MS. Biomechanical analysis of human ligament grafts used in knee-ligament repairs and reconstructions. Journal of Bone and Joint Surgery. 1984; 66(3):344-52. PMid:6699049.

Rodeo SA, Arnoczky SP, Torzilli PA, Hidaka C, Warren RF. Tendon-healing in a bone tunnel: a biomechanical and histological study in the dog. Journal of Bone Joint Surgery. 1993; 75(12):1795-803. PMid:8258550.

Rodeo SA, Kawamura S, Kim HJ, Dynybil C, Ying L. Tendon healing in a bone tunnel differs at the tunnel entrance versus the tunnel exit: an effect of graft-tunnel motion? The American Journal of Sports Medicine. 2006; 34(11):1790-800. http:// dx.doi.org/10.1177/0363546506290059. PMid:16861579.

Rodríguez C, García TE, Montes S, Rodríguez L, Maestro A. In vitro comparison between cortical and cortico-cancellous femoral suspension devices for anterior cruciate ligament reconstruction: implications for mobilization. Knee Surgery, Sports Traumatology, Arthroscopy. 2014; 23(8):2324-9. PMid:24839039.

Rupp S, Seil R, Schneider A, Kohn DM. Ligament graft initial fixation strength using biodegradable interference screws. Journal of Biomedical Materials Research. 1999; 48(1):70-4. http://dx.doi.org/10.1002/(SICI)1097-4636(1999)48:1<70::AIDJBM12>3.0.CO;2-P. PMid:10029152.

Rylander L, Brunelli J, Taylor M, Baldini T, Ellis B, Hawkins M, McCarty E. A biomechanical comparison of anterior cruciate ligament suspensory fixation devices in a porcine cadaver model. Clinical Biomechanics (Bristol, Avon). 2014; 29(2):230-4. http://dx.doi.org/10.1016/j. clinbiomech.2013.11.001. PMid:24321231.

Shen HC, Chang JH, Lee CH, Shen PH, Yeh TT, Wu CC, Kuo CL. Biomechanical comparison of Cross-Pin and Endobutton femoral fixation of a flexor tendon graft for anterior cruciate ligament reconstruction - A porcine femur-graft-tibia complex study. The Journal of Surgical Research. 2010; 161(2):282-7. http://dx.doi.org/10.1016/j. jss.2009.01.015. PMid:19524939.

To JT, Howell SM, Hull ML. Contributions of femoral fixation methods to the stiffness of anterior cruciate ligament replacements at implantation. Arthroscopy. 1999; 15(4):37987. http://dx.doi.org/10.1016/S0749-8063(99)70055-1. PMid:10355713.

Trump M, Palathinkal DM, Beaupre L, Otto D, Leung P, Amirfazli A. In vitro biomechanical testing of anterior cruciate ligament reconstruction: traditional versus physiologically relevant load analysis. The Knee. 2011; 18(3):193-201. http:// dx.doi.org/10.1016/j.knee.2010.04.011. PMid:20570155.

Weiler A, Peine R, Pashmineh-Azar A, Abel C, Sudkamp NP, Hoffmann RF. Tendon healing in a bone tunnel. Part I: biomechanical results after biodegradable interference fit fixation in a model of anterior cruciate ligament reconstruction in sheep. Arthroscopy. 2002a; 18(2):113-23. http://dx.doi. org/10.1053/jars.2002.30656. PMid:11830804.

Weiler A, Hoffmann RFG, Bail HJ, Rehm O, Südkamp NP. Tendon healing in a bone tunnel. Part II: histologic analysis after biodegradable interference fit fixation in a model of anterior cruciate ligament reconstruction in sheep. The Journal of Arthroscopic Related Surgery. 2002b; 
18(2):124-35. http://dx.doi.org/10.1053/jars.2002.30657. PMid:11830805.

Wilson TW, Zafuta MP, Zobitz M. A biomechanical analysis of matched bone-patellar tendon-bone and double-looped semitendinosus and gracilis tendon grafts. The Journal of Sports Medicine. 1999; 27(2):202-7. PMid:10102102.

Wu JL, Yeh TT, Shen HC, Cheng CK, Lee CH. Mechanical comparison of biodegradable femoral fixation devices for hamstring tendon graft - A biomechanical study in a porcine model. Clinical Biomechanics (Bristol, Avon). 2009; 24(5):43540. http://dx.doi.org/10.1016/j.clinbiomech.2009.02.003. PMid:19303181.

Zhang AL, Lewicky YM, Oka R, Mahar A, Pedowitz R. Biomechanical analysis of femoral tunnel pull-out angles for anterior cruciate ligament reconstruction with bioabsorbable and metal interference screws. The American Journal of Sports Medicine. 2007; 35(4):637-42. http:// dx.doi.org/10.1177/0363546506295181. PMid:17218654.

\section{Authors}

Ari Digiácomo Ocampo Moré1, André Luiz Almeida Pizzolatti', Eduardo Alberto Fancello ${ }^{1,2}$, Carlos Rodrigo de Mello Roesler ${ }^{1 *}$

${ }^{1}$ Laboratório de Engenharia Biomecânica - LEBm, Hospital Universitário, Universidade Federal de Santa Catarina UFSC, R. Prof Maria Flora Pausewang, S/N, Trindade, CEP 88040-900, Florianópolis, SC, Brazil.

${ }^{2}$ Grupo de Análise e Projeto Mecânico - GRANTE, Departamento de Engenharia Mecânica, Universidade Federal de Santa Catarina - UFSC, Florianópolis, SC, Brazil. 